\title{
OS SUJEITOS DISCURSIVOS EM REPORTAGENS DE FEMINICÍDIO NO JORNAL O POPULAR
}

\author{
The discursive subjects in femicide reports in the "O Popular" newspaper
}

\section{Los sujetos discursivos en informes de feminicidios en el periódico O Popular}

Kamilla Cristina da Cunha Santos Mestra em Comunicação pelo PPGCOM/UFG

kamillaccs@gmail.com

Ângela Teixeira de Moraes Professora Pós-doutora de Comunicação e Jornalismo da UFG prof.atmoraes@gmail.com

\section{Resumo}

Este artigo discute a construção dos sujeitos discursivos em reportagens sobre feminicídio no jornal impresso goiano $O$ Popular. Por meio da Análise de Discurso, busca-se verificar se há ou não mudança nessas construções discursivas após a promulgação da Lei do Feminicídio, editada em 2015, com corpus jornalístico selecionado antes e depois essa data, no período correspondente de 2012 a 2018. Parte-se de uma breve contextualização acerca dos conceitos de gênero e feminicídio, perpassando a noção de discurso e disputas de poder, concluindo que há uma tímida modificação do discurso dos sujeitos acerca da construção do feminicídio no jornal em questão.

Palavras-chave: Feminicídio. Jornalismo. Análise de discurso.

\begin{abstract}
This article discusses the construction of discursive subjects in reports on femicide in the Goiânia city newspaper "O Popular". By Discourse Analysis, we aim to analyze whether or not there was a change in these discursive constructions after the promulgation of the Law's Femicide, in 2015, in Brazil, with a journalistic corpus selected before and after that date, from 2012 to 2018. Our analysis starts from a brief contextualization about the concepts of gender and femicide, going throughout the notion of discourse and power disputes, leading to the conclusion that there was a timid modification of the subjects' discourse about the construction of femicide in that newspaper.
\end{abstract}

Keywords: Femicide. Journalism. Discourse analysis.

\section{Resumen}

Este estudio analiza la construcción de los sujetos discursivos en informes sobre feminicidio en el periódico impreso de Goiânia, O Popular. Mediante el Análisis del Discurso, buscamos analizar si hay un cambio en estas construcciones discursivas después de la promulgación de la Ley de Feminicidio, editada en 2015, en Brasil, con un corpus periodístico seleccionado antes y después de esa fecha, correspondiendo al período de 2012 hasta 2018. Empezamos con una breve contextualización sobre los conceptos de género y feminicidio, pasando por las 
nociones de discurso y disputas de poder, para concluir que hay una modificación tímida del discurso de los sujetos sobre la construcción del feminicidio en el periódico en cuestión.

Palabras clave: Feminicidio. Periodismo. Análisis del discurso.

\section{INTRODUÇÃO}

O feminicídio é uma grave violação dos direitos humanos das mulheres e de sua cidadania. É, ainda, a forma mais extrema de violência praticada contra as mulheres e meninas em decorrência de seu gênero. O Brasil ocupa os primeiros lugares no ranking mundial dos países que mais assassinam mulheres por sua condição de mulher, portanto, um dos países em que estas mais têm o seu direito à vida e à sua cidadania violada.

De acordo com o Atlas da Violência 2019, que analisou as incidências da violência no País, entre 2007 e 2017, houve um aumento de mais de 30\% de mulheres assassinadas. Somente no ano de 2017, foram mortas mais de 4.936 mulheres no Brasil. Outro dado importante apresentado pelo Atlas é o aumento da percepção em relação aos números de feminicídios no País, embora os dados ainda sejam aquém dos reais, visto que a subnotificação do crime ainda é alta.

De acordo com esses dados, o número de mulheres assassinadas dentro de casa aumentou mais de $17 \%$, das quais $29,8 \%$ foram assassinadas com o uso de arma de fogo. Goiás ocupa o $5^{\circ}$ lugar no ranking dos estados que mais assassinam mulheres no País, com uma taxa de 7,6 mulheres mortas para cada grupo de 100 mil. O estudo aponta, ainda, o aumento no assassinato de mulheres não negras de 1,6\%, enquanto o de mulheres negras cresceu $29,9 \%$ na década estudada, indicando que a desigualdade racial impera nas mortes de mulheres, quando observado o critério raça/cor.

Embora o feminicídio seja uma prática recorrente na história, os dados estatísticos são importantes para situarmos a gravidade do problema diante da sociedade atual. Essa prática que acomete mulheres a uma violência extremada e precisa ser evidenciada. De acordo com Blay (2008), a subnotificação nos dados dificulta o conhecimento real sobre as mortes resultantes por razões de gênero, fator importante para a criação e aplicação de ações que intentem reduzir a violência praticada contra as mulheres na sociedade. É o caso da implantação da Lei $\mathrm{n}^{\circ}$ 13.104, de 9 de março de 2015, a Lei do Feminicídio, que especifica o assassinato de mulheres "em razão de sexo feminino".

Aliado aos dados estatísticos, o jornalismo tem função importante na divulgação e disseminação de informações sobre o feminicídio na sociedade. Tem-se percebido um 
aumento no número de noticiários acerca dessa questão nos diferentes suportes midiáticos. Desse modo, faz-se importante compreender como está sendo construído o discurso jornalístico sobre o feminicídio, visto que a imprensa possui um papel estratégico na formação da opinião pública e das representações sociais.

Assim, este artigo pretende observar o feminicídio nas reportagens publicadas no jornal impresso goiano $O$ Popular, principal veículo de referência no estado de Goiás, com circulação diária. O corpus de trabalho foi composto por sete reportagens publicadas entre 2012 e 2018, uma matéria por ano, com o intuito de analisar se houve mudança no discurso jornalístico acerca dos sujeitos que aparecem nas reportagens sobre esse crime após a Lei do Feminicídio. Mais especificamente, busca-se verificar como estão sendo construídos os sujeitos discursivos envolvidos nos casos de feminicídio: o homem, a mulher, o judiciário e quais são as vozes silenciadas.

\section{GÊNERO, VIOLÊNCIA CONTRA AS MULHERES E FEMINICÍDIO}

Para falar de violência contra as mulheres na especificidade do feminicídio, é preciso compreender as questões que permeiam as relações de gênero e os direitos humanos das mulheres que implicam na efetivação da sua cidadania.

No Brasil, o conceito de gênero começou a ser estudado nos anos 1990, como uma forma de reflexão e questionamento dos papéis sexuais atribuídos a homens e mulheres como um modo de “construção cultural”. Para Scott (1995, p. 75), gênero é uma "criação inteiramente social de ideias sobre os papéis adequados aos homens e às mulheres. Trata-se de uma forma de se referir às origens exclusivamente sociais das identidades subjetivas de homens e mulheres". Esse conceito pode ser entendido, ainda, como uma categoria de análise social que pode visibilizar as questões das desigualdades sociais, políticas, econômicas e culturais existentes entre homens e mulheres. Desse modo, gênero compreende um campo por meio do qual o poder se articula.

Para Biroli (2018), é importante que se enxergue o conceito de gênero em confluência com outras variáveis, visto que a produção do gênero não ocorre isoladamente, mas perpassa outras relações de classe e raça/etnia, já que vivemos em um mundo de privilégios, onde não existe apenas o sexismo, mas, também, o classismo e o racismo. Os privilégios, de acordo com a autora, são resultantes das relações de poder que acendem as desigualdades sociais. No caso específico do gênero, as desigualdades de poder são decorrentes das construções sociais de papéis de gênero. Essas relações não tratam apenas das interações entre homens e 
mulheres, mas também da relação entre os próprios homens e as próprias mulheres em classes sociais diferentes.

Teles (2017) reflete que as desigualdades de gênero ou de raça/etnia são tão naturalizadas, que atuam de forma quase imperceptíveis na sociedade. $\mathrm{Ou}$ seja, as desigualdades são discursos construídos que carregam a ideologia hegemônica de que as diferenças sociais entre homens e mulheres decorrem da essência da natureza. Daí, portanto, é que deve ser adotado o conceito de gênero, de modo a denunciar essa ordem social e institucional que determina como deve ser o papel do homem e o papel da mulher. Dessas desigualdades sociais atribuídas aos papéis de gênero derivadas das relações de poder é que ocorre e se naturaliza a violência de gênero.

A violência de gênero é onipresente, é o resultado de condutas apreendidas tanto por suas vítimas como por seus agressores. É legitimada socialmente, entendida como natural. $O$ fenômeno cíclico da violência reflete a acomodação da sociedade diante do problema: lua de mel, tensão nas relações, acirramento dos conflitos entre ambos até que explodem em violência aberta; e seguida, vem o arrependimento, a reconciliação e, novamente a lua de mel, dando continuidade ao ciclo (TELES, 2017, loc. $683)$.

A violência de gênero é um continuum que vai desde a violência psicológica, moral, física, chegando, muitas vezes, ao feminicídio. Ela atinge todas as esferas, as públicas e as privadas, e nelas são construídos os papéis atribuídos aos homens e às mulheres. Enquanto o gênero masculino é construído para o público, o feminino é destacado para o privado. E é nesse espaço privado em que ocorrem as principais punições, em caso de descumprimento do papel atribuído socialmente às mulheres. É nessa esfera, nas residências, no lar, em que ocorre a maioria das violências de gênero, incluindo a violência doméstica e o feminicídio. O Atlas da Violência 2019 aponta que houve um crescimento de quase 20\% de assassinatos de mulheres dentro do próprio lar, entre os anos de 2007 e 2017.

Considera-se feminicídio a violação dos direitos humanos e da cidadania da mulher, uma vez que desconsidera a mulher como sujeito humano, portadora de direitos na sociedade. O conceito foi trazido para o contexto latino-americano em meados dos anos 2000, por Marcela Lagarde, deputada e estudiosa feminista mexicana, como forma de investigar e denunciar as diversas mortes e desaparecimentos de mulheres no México, desde a década de 1990, principalmente na Ciudad Juarez, no departamento de Chihuahua, cidade que faz fronteira com os Estados Unidos. 
Lagarde (2008), em seus estudos e publicações, adota o termo feminicídio ao invés da tradução literal femicídio para falar do assassinato de mulheres em condições de gênero, por considerar que o segundo termo não contemplaria a totalidade do conceito e seria reduzida ao oposto de homicídio. "Para diferenciá-lo, preferi utilizar feminicídio e denominar assim o conjunto de violações aos direitos humanos das mulheres que incluem os crimes e os desaparecimentos de mulheres e que, estes, fossem identificados como crimes de lesa humanidade" (p. 215-216, tradução nossa).

A partir da divulgação dos fatos que estavam ocorrendo na cidade mexicana, foi possível expandir os estudos sobre o feminicídio na América Latina e cobrar políticas de segurança pública para coibir esse tipo de crime. Hoje, já são 17 países a utilizar a terminologia dentro do código penal, como forma de agravante ao homicídio (ROMIO, 2017). No Brasil, a Lei n$^{\circ}$ 13.140, Lei do Feminicídio, foi aprovada em 9 de março de 2015 e institui:

Feminicídio é o homicídio cometido contra a mulher por razões da condição de sexo feminino.

$\S 2^{\circ}$ Considera-se que há razões de condição do sexo feminino quando envolve:

I - violência doméstica e familiar;

II - menosprezo ou discriminação à condição de mulher (BRASIL, 2015).

O crime foi instituído como uma instância qualificadora do homicídio, inserindo-se no rol dos crimes hediondos. Considera-se que a legislação específica foi um avanço no reconhecimento das diferenciações sociais e culturais enfrentadas pelas mulheres. É um marco no combate à violação dos direitos humanos das mulheres e no avanço da cidadania. Entretanto, ainda há muito o que avançar, visto que a problemática do feminicídio, além de jurídico, é, também, social, histórico e cultural.

\subsection{O percurso metodológico}

De modo a compreender como se dá a construção de sentido dos sujeitos discursivos em reportagens sobre o feminicídio no jornal $O$ Popular, este trabalho utiliza dispositivos teórico-analíticos da AD para realizar a investigação.

Orlandi (2007) afirma que a Análise de Discurso (AD) busca compreender a linguagem como algo que faz sentido, levando em consideração a sua realidade histórica e social. Ou seja, a AD não trabalha com a língua de maneira fechada em si própria, mas com o discurso, compreendido como um objeto sócio-histórico. "Nos estudos discursivos, não se 
separam forma e conteúdo e procura-se compreender a língua não só como uma estrutura, mas sobretudo como acontecimento" ${ }^{1 "}$ (p. 19), e a AD busca ultrapassar os seus limites e mecanismos de interpretação como parte dos processos de significação. Fairclough (2001, p. 91), entende o discurso como "um modo de ação, uma forma em que as pessoas podem agir sobre o mundo e especialmente sobre os outros, como também um modo de representação". É, ainda, uma prática política que "estabelece, mantém e transforma as relações de poder e as entidades coletivas (classes, blocos, comunidades, grupos) entre as quais existem relações de poder” (p. 94), transformando os significados do mundo nas relações de poder.

Poder pode ser compreendido como um feixe de forças simbólicas assimétricas que disputam o domínio e o estabelecimento da ordem uma sobre a outra. O poder simbólico, para Bourdieu (1989), compõe estruturas estruturantes que atuam de modo a reproduzir a ordem social estabelecida. Este poder é exercido pelos aparelhos ideológicos de Estado, ou seja, a escola, a igreja, a família e a mídia. Thompson (2002) compreende o poder simbólico como um poder cultural, que nasce da transmissão e recepção de informações e discursos pelos meios de comunicação, que são os principais meios de propagação de significados das formas simbólicas. Para compreender como esse poder simbólico se desenvolve no discurso jornalístico acerca do feminicídio, analisaremos de que modo esses sujeitos estão sendo construídos e considerados pelo jornal goiano após a Lei do Feminicídio.

Optou-se como objeto empírico de pesquisa o jornal impresso diário O Popular, pertencente ao Grupo Jaime Câmara, que comporta outros 24 veículos de comunicação situados em Goiás, Tocantins e Distrito Federal, sendo considerado um dos maiores jornais de referência do Centro-Oeste. Para a análise de discurso, escolheu-se uma publicação jornalística referente a um dia de cada ano compreendido entre 2012 a 2018, totalizando sete reportagens, e serão apresentadas no quadro a seguir:

1 Acontecimento discursivo é uma noção foucaultiana que propõe reconstituir atrás do fato toda uma rede de discursos, poderes, estratégias e práticas. Os sentidos que permeiam os discursos sobre os fatos são ancorados na história, e surgem na forma de uma irrupção singular. 
PROGRAMA DE PÓS-GRADUAÇÃO EM COMUNICAÇÃO DA UNIVERSIDADE FEDERAL DE SANTA MARIA

\begin{tabular}{|l|l|l|l|}
\hline \multicolumn{1}{|c|}{ ANTES DA LEI } & \multicolumn{2}{c|}{ DEPOIS DA LEI } & Data \\
\hline \multicolumn{1}{|c|}{ Título } & Data & \multicolumn{1}{c|}{ Título } & $18 / 04 / 2015$ \\
\hline $\begin{array}{l}\text { Justiça condena assassinos de } \\
\text { publicitária }\end{array}$ & $12 / 10 / 2012$ & Funkeira goiana é morta no Rio & $07 / 10 / 2016$ \\
\hline A morte pelas ondas do rádio & $12 / 04 / 2013$ & $\begin{array}{l}\text { Assassinos já haviam sido } \\
\text { denunciados }\end{array}$ \\
\hline $\begin{array}{l}\text { Homem mata os três filhos, ex- } \\
\text { mulher e se suicida }\end{array}$ & $08 / 01 / 2014$ & Jovem é encontrada morta & $26 / 04 / 2017$ \\
\hline
\end{tabular}

Quadro 1 - Reportagens sobre feminicídio de 2012 a 2018

Fonte: Das autoras.

A escolha das reportagens contempla publicações anteriores e posteriores à Lei do Feminicídio, que constituem a ordem do dia, ou seja, aparecem na capa do jornal, sendo manchetes ou não. Outros critérios envolvem a proximidade com o estado de Goiás, além da questão da morte de mulheres por questões de gênero que foram cometidas por homens maiores de 18 anos. A análise caminhará para uma comparação dos sentidos produzidos pelos sujeitos presentes nas reportagens, interessando saber se os discursos produzidos se modificaram após a Lei e, no caso de mudanças, qual(is) sujeito(s) são responsáveis por elas.

\subsection{Os sujeitos discursivos do feminicídio}

$\mathrm{Na}$ construção do discurso jornalístico é preciso considerar as estratégias pensadas para a tessitura do texto. Há uma seleção de fatos, enunciados, sujeitos e silenciamentos que são comandadas pelo próprio sujeito jornalista e pela empresa midiática. Não existe discurso neutro, nem se pode afirmar que o jornalismo apenas reproduz as falas tais quais são ditas. É necessário ter em conta que o próprio sujeito que constrói o discurso é formado por outros discursos, possui suas crenças e ancoragem cultural e social. "Quando nascemos, os discursos já estão em processo e nós é que entramos nesse processo. Eles não se originam em nós" (ORLANDI, 2007, p. 35). Nesse sentido, existe também uma ordem discursiva jornalística que se soma à subjetividade do profissional, moldando o olhar com o qual ele se dirige aos fatos.

Os sujeitos enquanto fontes aparecem de vários modos na construção jornalística. As principais vozes que constroem o discurso jornalístico referente ao crime de feminicídio são provenientes do discurso jurídico, representadas pelos juízes e juízas, delegados e delegadas, advogados e advogadas e policiais. Essas vozes remetem tanto ao acusado, quando à contextualização do caso e do feminicídio. A segunda voz mais presente nessa construção é a do acusado, seja porque está vivo e preso, na maioria das vezes, quando este não cometeu suicídio, seja por meio da própria instituição judicial que fala por eles. A terceira voz, menos 
frequente, é a das vítimas que são representadas nas vozes de familiares, amigos e amigas, que servem como vozes em defesa dessa mulher.

Há, ainda, as vozes silenciadas, que não aparecem no discurso das reportagens analisadas, aquelas dos movimentos sociais, outras do campo da pesquisa social, as dos psicólogos, historiadores, que poderiam tratar o feminicídio como um problema social, para além do jurídico, e apontar os contextos sócio-histórico-culturais que envolvem os casos. Essas vozes auxiliariam a contextualização mais ampla sobre a violação da cidadania e dos direitos humanos das mulheres.

\section{Os acusados}

Os acusados são majoritariamente pertencentes ao gênero masculino, com idade entre 23 e 65 anos, e possuíam alguma relação íntima com as vítimas, sendo maridos, ex-maridos, noivos, namorados e genitores, demonstrando quase unanimidade no entendimento de que o feminicídio é apenas o íntimo (CARCEDO e SAGOT, 2000), de cunho doméstico (ALMEIDA, 1998; ROMIO, 2017) e não decorrente de outras situações. Somente em um dos casos analisados, na reportagem de 2012, não havia envolvimento afetivo ou familiar entre a vítima e os assassinos.

Quando caracterizados como pais, esses homens são apresentados ora como bom pai, aquele que provê a casa, possui renda e boa relação com os filhos e filhas, ora como mau pai, aquele que não possui profissão ou é uma pessoa violenta com a prole. Normalmente, os filhos/as aparecem vinculados aos acusados, quando aqueles foram atingidos pela violência direta que resultou na publicação da reportagem jornalística.

Como exemplo de "bom pai", pode-se citar o técnico de informática David Medrado, de 35 anos, cujas vozes enunciativas figuram o homem como um pai presente, embora fosse violento com a ex-esposa, com a qual viveu por quase uma década. Com a filha, possuía uma boa relação:

David "dava muito trabalho", ameaçava a irmã com frequência e buscava a filha única do casal sempre para passear (O POPULAR, 2016, p. 10, ed. 22.924).

"Ele vinha de uma a duas vezes de moto. Parava e conversava com a filha no portão. O contato dele era só com a filha" (O POPULAR, 2016, p. 11, ed. 22.924). 
O mau pai é retratado no discurso como aquele mau-provedor, que não possui profissão definida, cuja esposa é a responsável pelo sustento o lar, assim como aquele que é violento com os próprios filhos. É o caso Wendel Roberto da Silva, de 37 anos, que assassinou a esposa a facadas, em frente às próprias filhas pequenas, que já haviam presenciado várias brigas do casal. $\mathrm{O}$ discurso sobre esse sujeito se volta mais para o fato de que ele não resguardava a família, do que para o de este ser um feminicida, reforçando que houve transgressão ao discurso normativo dos papéis de gênero, que constrói o genitor como o provedor da família e estabelece como este deve agir enquanto ser social (SCOTT, 1995).

"ele deixou as filhas para trás e fugiu" (O POPULAR, 2018, p. 12, ed. 23.628).

não gostava do jeito que o genro se comportava, pois ele não resguardava nem as filhas (O POPULAR, 2018, p. 12, ed. 23.628).

"uma vez, a neta ligou dizendo que o pai estava querendo matar a mãe enforcada. Ele só não matou, porque a irmã de quatro anos entrou na frente e se jogou no corpo da mãe" (O POPULAR, 2018, p. 12, ed. 23.628).

Quando não há filhos envolvidos diretamente no crime, a construção discursiva recai sobre o relacionamento do casal e as motivações que provocaram um "surto" ou "transtorno" nesse homem, que era, em síntese, um trabalhador ou um empresário, não possuía passagem pela polícia ou não demonstrava ser capaz de matar. Ou seja, são os históricos "criminosos passionais", aqueles que matam em nome do amor, por ficarem transtornados com o fim do relacionamento ou pelo medo de perder a pessoa amada para outro. Entretanto, mesmo quando o assassino já tinha passagem pela polícia, ele é retratado como um amante passional. Essa construção surge principalmente na voz jurídica, por delegados ou advogados presentes, mas, em alguns casos, os agressores possuem a voz no texto, arquitetando um discurso de passionalidade, emoção súbita, ou seja, algo que não é comportamento comum a esses homens. Esse tipo de discurso se volta para uma culpabilização da vítima pelas ações que levaram a um acesso de "loucura momentânea" desses homens "apaixonados", visto que, na construção discursiva, foram elas que provocaram tal situação. O discurso jornalístico não contesta o fato de que eles, os feminicidas, são os responsáveis por suas próprias ações, que resultam de uma construção histórica de subordinação do corpo da mulher enquanto propriedade masculina ou da família. 
Ele revelou à ex-namorada que a feria para ela aprender a nunca mais machucar o coração de um homem (O POPULAR, 2013, p. 4, ed. 21.650).

o dono de vans teria "surtado" ao receber imagens pelo celular de uma suposta traição de Amanda (O POPULAR, 2015, p. 10, ed. 22.386).

Confessou ter matado a esposa e disse ter ficado transtornado, "porque ela estava estudando e ele não" (O POPULAR, 2017, p. 14, ed. 23.125).

O que se apreende é que não houve uma mudança discursiva acerca dos acusados, visto que tanto nas reportagens antes da Lei, quanto nas posteriores, os acusados continuaram sendo retratados como loucos momentâneos, doentes ou cegos de paixão, que foram motivados por um sentimento "irracional" a cometer tal crime. Esse fator ocorre porque a imagem dos acusados é construída ao serem destacadas as motivações que levaram ao crime. Enquanto a motivação for maximizada para o fato de a vítima ter decidido exercer o seu direito ao divórcio ou ao rompimento da relação e constituição de nova família, e não for apontada como uma problemática social, construída historicamente e reforçada pelos papéis de gênero instituídos, acredita-se que o discurso sobre os acusados não sofrerá modificações.

\section{As vítimas}

As mulheres assassinadas por razões de gênero possuem idade compreendida entre 19 e 56 anos, as crianças, filhos e filhas, de 3 a 13 anos. São esposas, ex-esposas, ex-namoradas. A metade das mulheres assassinadas (aquelas que tinham alguma relação afetiva com o acusado) foi retratada enquanto figura materna, outras não possuíam filhos e foram construídas como mulheres de família e trabalhadoras.

As mulheres são retratadas nas vozes dos familiares e de amigas/os. Essas vozes servem como testemunhas oculares do caso, além de servirem como defesa da mulher, já que são elas que explicam o continuum de violência sofrida. Esses sujeitos podem ser compreendidos como a voz da resistência, enquanto as vozes da instituição jurídica e dos próprios acusados tendem a culpabilizar a vítima pelo seu destino trágico. 


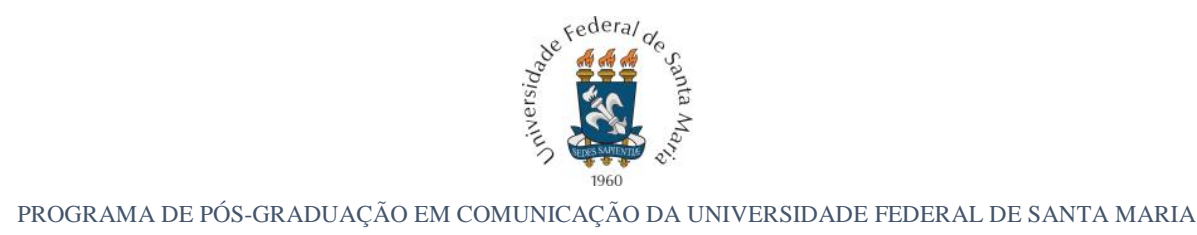

A mãe da publicitária, Tânia Mara Arruda Borges, que após a morte da filha buscou as autoridades e a imprensa para que o crime não ficasse impune (O POPULAR, 2012, p. 2, ed. 21.462).

A irmã de Maria Divina, Verônica Pereira de Souza, procurou a Deam e notificou o desaparecimento da dona de casa (O POPULAR, 2014, p. 9, ed. 21.921).

Familiares estranharam o sumiço dela nas redes sociais, por onde eram acostumados a trocar mensagens durante o dia (O POPULAR, 2017, p. 14, ed. 23.125).

Nos dados analisados, algumas mulheres exerciam atividades econômicas, embora consideradas atividades inferiores às realizadas pelos homens. Algumas eram donas de casa e havia, ainda, aquelas que eram as únicas provedoras do lar, como é o caso da dona de casa Divina Pereira, de 30 anos que, embora seja retratada como "dona de casa", ela "sustentava os três filhos com os rendimentos da herança do pai" (O POPULAR, 2014, p. 9, ed. 21.921). O que a teoria diverge dos dados analisados é que, embora haja uma desigualdade econômica entre a vítima e o acusado, a maioria delas já estava separada desses homens e não dependiam financeiramente dos mesmos, o que demonstra que a questão está muito além da desigualdade econômica, mas se apresenta numa escala macrossocial e cultural.

Outra marca da construção discursiva sobre as mulheres assassinadas é a figura materna ou de cuidado próximo à família, de modo a justificar seus atos e comprovar que eram mulheres "decentes" e socialmente comprometidas com os papéis que lhe cabiam, enquanto esposas ou mães e trabalhadoras. Os enunciados demonstram, ainda, que as vítimas sofriam violência, mas que não estavam satisfeitas com os relacionamentos, e pretendiam sair desta relação aterradora de violência, que infelizmente teve um fim antes de consumar a separação. 
Apesar de estar noivo do ex-integrante da banda de funk, Amanda não se mostrava satisfeita com o relacionamento, segundo disse Emily, de 11 anos, filha de Amanda (O POPULAR, 2015, p. 10, ed. 22.386).

Uma amiga da família, que pediu para não ser identificada, acredita que Amanda tentava se livrar do noivo, depois de ver que ele era uma pessoa desequilibrada (O POPULAR, 2015, p. 10, ed. 22.386).

A confissão de Lucas, alegando ciúmes, causou espanto na avó da estudante, que se identificou apenas como Maria de Fátima. Ela afirmou que não acreditava no sentimento alegado. "A gente tinha a impressão que ele nem tinha ciúmes dela” (O POPULAR, 2017, p. 14, ed. 23.125).

Jadisson revela que a filha não havia se separado, mas pretendia levar adiante o plano que vinha sendo adiado por medo da reação de Wendel. Ela já tinha sofrido agressões anteriores. "Eu dizia pra ela manter em segredo, não contar nada e que iria ajudá-la a ir embora. Eu também tinha medo dele fazer alguma coisa com ela, mas estava segurando na mão de Deus" (O POPULAR, 2018, p. 12, ed. 23.628).

Percebe-se que os discursos construídos sobre as vítimas, bem como o que ocorreu com os acusados, não sofreram modificação a partir da promulgação da Lei. Os acusados foram construídos, antes e após a lei, em 2015, como possessivos, controladores, “desequilibrados". Já as vítimas, mesmo sendo cultivadas enquanto mães ou mulheres que cumpriam os seus papéis familiares, são culpabilizadas pelo crime misógino cometido contra elas próprias e, ainda, com a função de defender-se das acusações proferidas pelo feminicida, pela instituição judicial e pela própria construção do jornal.

\section{O discurso jurídico e o feminicídio}

Enquanto as vozes das vítimas e dos acusados servem para construir o enredo do jornal, a voz jurídica é a responsável por contextualizar o fato ocorrido, demarcando as motivações para o crime, bem como dar um sentido de punibilidade, inferindo questões de segurança pública. É ela que carrega junto a si as principais construções de sentido acerca do feminicídio, bem como, ela é uma das responsáveis por promover as mudanças discursivas acerca desse fato, visto que as mudanças na legislação tendem a promover mudanças nas construções dos discursos jurídicos (MELLO, 2017), embora, quando se trate de crimes de feminicídio, tão somente os termos vem mudando na letra da Lei no decorrer da história, sem apresentar mudanças relevantes em seu contexto social e cultural.

A voz jurídica, por meio de delegados e delegadas, nas reportagens analisadas antes da lei do feminicídio, incide em uma formação discursiva sobre a passionalidade do crime, cujas motivações apontadas pelas próprias construções discursivas, seriam derivadas da relação do 
casal e provocadas pela vítima, visto que o ciúme e a vingança são os principais pontos destacados nas ocorrências. Além de instruir sobre as motivações que resultaram em tal crime, o discurso jurídico atua no papel de caracterizar o criminoso e os seus atos. É a voz da consciência moral que perdura na sociedade. Ou seja, além de resguardar a segurança, a polícia também exerce a função de vigilante da "moral e dos bons costumes".

Myrian Vidal acentua que a morte de Mari José deve servir de alerta para as pessoas que se envolvem com desconhecidos por meio de emissoras de rádio e da rede social. "As pessoas não devem abrir sua casa, sua vida a outros de quem não tem nenhuma referência" (O POPULAR, 2013, p. 4, ed. 21.650).

Durante as investigações, a delegada soube que há uma semana a dona de casa havia postado na rede social a foto de um homem que, conforme destacou, seria namorado dela. Este fato, segundo a delegada, teria motivado a tragédia (O POPULAR, 2014, p. 9, ed. 21.921).

O delegado Fábio Salvadorelli, da Divisão de Homicídios da Baixada Fluminense (BHBF), classificou as imagens como "cruéis a ponto de chocar até os policiais" (O POPULAR, 2015, p. 10, ed. 22.386).

O desembargador Luiz Claudio Veiga Braga, da Coordenação Estadual da Mulher em Situação de Violência Doméstica e Familiar do Tribunal de Justiça de Goiás disse que [...] Ele (David) teve um comportamento primitivo, chocante. (O POPULAR, 2016, p. 10, ed. 22.924).

Ainda, a partir de 2015, o enunciado feminicídio foi incluído no discurso jurídico e, por consequência, no discurso jornalístico. Entretanto, quando aparece, na maioria das vezes, surge como uma substituição ao termo homicídio sem contextualização do crime ou discussão acerca das disputas referentes às relações de gênero que resultam neste tipo de crime.

Ele já foi indiciado por feminicídio (O POPULAR, 2015, p. 10, ed. 22.386).

A lei tipificando o crime de feminicídio foi sancionada em março deste ano pela presidente Dilma Rousseff (O POPULAR, 2015, p. 10, ed. 22.386).

Segundo o delegado, Lucas deve ser indiciado por homicídio qualificado, ocultação de cadáver e fraude processual, já que tentou tirar vestígios da casa. O caso deve ser caracterizado como feminicídio (O POPULAR, 2017, p. 14, ed. 23.125).

$\mathrm{Na}$ análise do discurso jurídico sobre o feminicídio percebeu-se algumas mudanças na construção discursiva após a Lei, promulgada em 2015. Embora, majoritariamente, o jornal, por meio de suas estratégias de construção, e algumas falas, ainda retrate o feminicídio como 
um crime passional, há, em alguns momentos, uma elucidação acerca de um problema maior, clamando para a atenção para uma mudança social, que deveria ocorrer por meio do Estado e da educação.

A reportagem Funkeira Goiana é morta no Rio (2015) foi a primeira a ser tipificada como feminicídio no jornal $O$ Popular após a promulgação da Lei. Num primeiro momento, observou-se que o termo feminicídio aparece de modo descontextualizado, sem alusão à legislação ou o porquê de o crime ter sido tipificado como tal. Num segundo momento, podese inferir que a explicação para a tipificação do crime está no relato em si, que apresenta uma narração detalhada sobre o crime que culminou na morte da dançarina Amanda Bueno, finalizando com o depoimento da amiga, Valeska Popozuda, denunciando o crime como resultante de violência doméstica. O texto serviu para aludir que o feminicídio em si é resultante de um continuum de violência que submete mulheres, todos os dias, no mundo inteiro, não importando a classe social. Desde donas de casa até empresárias podem ser vítimas dessa violência, que muitas vezes termina em assassinato. Essa reportagem é o marco da mudança dos termos de crime passional ou homicídio para feminicídio no jornal $O$ Popular.

Mais recentemente, na reportagem de 2018, o discurso do jornal abriu espaço para a discussão sobre o fato de o feminicídio não ser apenas um problema jurídico, mas que também deriva de uma misoginia social. Esses discursos continuam sendo focalizados na voz jurídica, embora passe a mesclar com a própria voz do sujeito que escreve a reportagem, por meio de falas indiretas. 
Não aceitar o termo feminicídio é mais um ato machista. A mulher, além de estar tão exposta à violência quanto o homem, ainda corre o risco de morrer dentro de casa. Ana Elisa Gomes. Delegada da Mulher de Goiânia (O POPULAR, 2018, p. 13, ed. 23.628).

Titular da Delegacia Especializada no Atendimento à Mulher (Deam), Ana Elisa Gomes, reconhece no aumento de casos de feminicídios em Goiás um fenômeno social que resulta da banalização da violência ( $O$ POPULAR, 2018, p. 13, ed. 23.628).

Em Goiás, ela destaca o machismo facilmente detectável na sociedade como um elemento que fortalece pensamentos e ações que fundamentam os atos violentos. "Ainda somos muito machistas. Somos muito mal educados, e não só culturalmente, mas socialmente também. A gente não sabe se comportar. Somos uma sociedade machista. De homens e mulheres machistas" (O POPULAR, 2018, p. 13, ed. 23.628).

“O Estado precisa se posicionar mais, instruir mais a população e investir mais na estrutura, ter mais delegacias, um efetivo maior. $\mathrm{O}$ que precisa mesmo é uma posição mais expressiva do Estado para combater esses números. Vamos ter que começar a falar de gênero nas escolas. As pessoas têm que começar a entender que precisamos desmistificar algumas coisas nas escolas, senão teremos para sempre a mulher treinada para cuidar das coisas de casa e o homem para todo o resto", defende (O POPULAR, 2018, p. 13, ed. 23.628).

Há espaço no discurso jornalístico para apontar o crime de feminicídio como um "fenômeno social", que deriva de uma cultura misógina, e não apenas como uma problemática de insegurança jurídica, cuja solução é focada na educação e deve ser construída pela base, clamando por um posicionamento do próprio Estado enquanto Poder responsável pela formação ideológica social vigente. Fairclough (2001) acredita que as mudanças discursivas remetem a mudanças sociais, logo, é possível pensar que as mudanças no discurso sobre feminicídio podem contribuir com a luta das mulheres e dos movimentos sociais acerca da eliminação dessa construção social e cultural de culpabilização da mulher pela violência sofrida. A educação é um sistema de construção e representações simbólicas importantes na concretização de pensamentos na sociedade, bem como o próprio jornalismo, que possui o poder de evidenciar e silenciar determinadas questões, bem como inferir na construção da realidade social (TRAQUINA, 2000).

\section{Os não-ditos discursivos: as vozes silenciadas}

De acordo com Orlandi (2007), é preciso escutar o não dito naquilo que foi dito, uma presença de uma ausência necessária, visto que as relações de sentido são construídas tanto pelos interdiscursos quanto pelo intertexto. Segundo a autora, os esquecimentos são da ordem 
do interdiscurso, que são afetados pelas memórias esquecidas discursivamente. Destaca que há duas formas de esquecimento no discurso: a "ordem da enunciação", ou seja, a forma como o discurso é construído de uma maneira e não de outra, e o "esquecimento ideológico" (ORLANDI, 2007, p. 35). Na primeira forma, segundo a autora, o esquecimento nos induz a pensar e a construir a realidade social a partir dos ditos e dos não ditos, o que nos leva a pensar que só podemos dizer algo de uma única forma. E o esquecimento afeta a maneira pela qual somos dissimulados pelas ideologias presentes no discurso, fazendo-nos pensar que o que dizemos vem de nós mesmos e não de uma construção ancorada socialmente.

No discurso acerca do feminicídio analisado nessas reportagens, observou-se duas formas de silenciamentos na construção de sentidos, o apagamento da discussão sobre raça/cor e as vozes dos movimentos sociais. O silenciamento do discurso sobre raça/cor demonstrada no jornal é muito significante, visto que todas as reportagens analisadas abordavam o assassinato de mulheres brancas, fato comprovado pelas imagens divulgadas nas capas e no conteúdo ilustrativo das reportagens. É preciso considerar que há uma invisibilidade do assassinato de mulheres negras no jornal O Popular, principalmente se considerarmos que o Estado de Goiás perdura na quinta colocação entre os estados que mais assassina mulheres negras no país, de acordo com o Atlas da Violência 2019. Esse discurso não aparece em nenhuma das reportagens analisadas para esse estudo, antes e após 2015, nem faz referência a cor/raça das mulheres assassinadas.

Outro silenciamento observado foram as vozes dos movimentos sociais, bem como de pesquisadoras e especialistas na temática de gênero e violência contra a mulher, que não aparecem em nenhuma das reportagens do material analisado. Essas vozes poderiam levantar questões acerca da cultura violenta a qual as mulheres são submetidas, as desigualdades econômicas e salariais, as questões relacionadas aos papéis de gênero instituídos socialmente. Nenhuma dessas questões são levantadas, e quando o são, continuam sendo pelas vozes das instituições jurídicas presentes.

Diante do exposto, apresentamos o quadro 2 com as modificações, ou não, encontradas na análise:

\begin{tabular}{|l|l|l|}
\hline SUJEITOS & \multicolumn{1}{|c|}{ DISCURSOS } & \multicolumn{1}{|c|}{ HOUVE } \\
MUDANÇA?
\end{tabular}




\begin{tabular}{|l|l|l|}
\hline $\begin{array}{l}\text { Sobre átimas } \\
\text { vítion }\end{array}$ & $\begin{array}{l}\text { As vítimas continuam sendo retratadas como mães, filhas, cuidadoras } \\
\text { do lar, trabalhadoras, ou seja, mulheres que seguiam os papéis de } \\
\text { gênero instituídos socialmente. }\end{array}$ & Não \\
\hline $\begin{array}{l}\text { Sobre os } \\
\text { sujeitos } \\
\text { jurídicos }\end{array}$ & $\begin{array}{l}\text { Os sujeitos jurídicos continuam sendo retratados como os “vigilantes } \\
\text { da moral e dos bons costumes". Antes da Lei, eles serviam como voz } \\
\text { dos acusados e justificavam os crimes destes a partir da } \\
\text { culpabilização da vítima. Após a Lei, em 2015, é possível perceber } \\
\text { que há um espaço maior para a problematização social do tema, } \\
\text { como resultante de uma cultura misógina e da banalização da } \\
\text { violência. }\end{array}$ & \\
\hline $\begin{array}{l}\text { Vozes } \\
\text { silenciadas }\end{array}$ & $\begin{array}{l}\text { Tanto antes como após a Lei, não é discutida a questão raça/cor nas } \\
\text { reportagens. Bem como não há presença de movimentos sociais, } \\
\text { pesquisadoras de gênero e direitos humanos, antropólogas, cientistas } \\
\text { sociais, psicólogas, poderiam ser fontes presentes nas reportagens } \\
\text { acerca do feminicídio. São vozes silenciadas que poderiam ampliar o } \\
\text { debate acerca de questões sociais, culturais e científicas. }\end{array}$ & \\
\hline $\begin{array}{l}\text { Qualificação } \\
\text { do crime }\end{array}$ & $\begin{array}{l}\text { Antes da Lei, os assassinatos contra as mulheres foram classificados } \\
\text { como homicídios, tragédias familiares ou crimes passionais. Após a } \\
\text { Lei, ainda apareceu na reportagem de 2017 como crime passional, no } \\
\text { entanto, nas demais, todas foram classificadas como feminicídio. }\end{array}$ & \\
\hline
\end{tabular}

Quadro 2 - Mudanças discursivas no jornal

Fonte: das autoras.

A partir dos dados analisados, não se constataram mudanças acerca da construção discursiva sobre os acusados e as vítimas, visto que o discurso jornalístico ainda se firma, principalmente, nas motivações que levaram ao crime e na relação íntima que esses personagens apresentavam à época do crime. No entanto, percebeu-se uma tendência maniqueísta de perpetuação dos papéis de gênero empregados aos feminicidas, sendo bons ou maus pais, bons ou maus maridos; e às mulheres, atreladas, principalmente, ao papel maternal do cuidado, com a prole, com a família.

Todavia, observaram-se algumas mudanças na construção discursiva do jornal acerca do feminicídio após a promulgação da legislação específica, em março de 2015, principalmente na voz jurídica. Primeiro, o crime passou a ser denominado e tipificado como feminicídio, seguindo o termo jurídico oficial e segundo, abriu-se espaço para salientar que o feminicídio não é apenas um crime comum, mas um crime machista que decorre de problemáticas sociais e culturais enraizadas historicamente em nossa sociedade. Além de apontar que a solução não decorre apenas da punição, mas, também, do investimento na educação de base que discuta os papéis de gênero instituídos até hoje.

\section{CONSIDERAÇÕES FINAIS}

A partir das sete reportagens analisadas, pode-se constatar que houve uma tímida modificação acerca do discurso sobre o feminicídio nas reportagens estudadas a partir da Lei do Feminicídio, em 2015. Essa modificação se mostrou mais presente no ano de 2018. De 
acordo com os resultados, o que antes era caracterizado apenas como crime passional, cometidos em nome da "paixão", agora passou a ser representado como um crime "machista". Quando antes só era divulgado o crime como um problema jurídico, que necessitava de punição, porque era um problema de segurança pública, a partir da Lei ${ }^{\circ} 13.104$, promulgada em 9 de março de 2015, passou-se a discutir o fato como um problema que envolve violência doméstica e um "fenômeno social" que deriva do machismo cultural existente na sociedade.

Observou-se, ainda, que a reportagem de 2018 onde se abordou, exclusivamente, o tema do feminicídio, apontou algumas soluções para o problema, mesmo que não sejam soluções simples. O discurso reforça que a educação é fundamental nessa luta, que deve ser abraçada pelo Estado, sem medo de discutir questões que envolvem relações de gênero e fortalecer o emparelhamento jurídico, como medida de real punição desses crimes. Há ainda as construções de apagamento, como os discursos que versam sobre as questões étnicas e raciais, bem como os movimentos sociais que não possuem vozes no discurso. Nesse ponto, não houve modificação antes ou após a legislação específica sobre o assassinato de mulheres.

O feminicídio é uma realidade cada dia mais presente em nosso cotidiano. Diante disso, resulta importante saber como esse crime está sendo construído discursivamente nos produtos jornalísticos. Nesta pesquisa sobre o jornal impresso goiano O Popular, perceberamse que as mudanças discursivas ocorreram apenas na voz jurídica, desse modo, é importante que o discurso jornalístico amplie as fontes consultadas para além do judiciário. Buscar os movimentos sociais, pesquisadores(as), psicólogos (as) e historiadores (as), para ampliar o debate em escala macrossocial é muito importante, pois amplia o olhar sobre o feminicídio não como um crime individualizado, acarretado por violência doméstica, mas como decorrente de uma estrutura sociocultural que viola a cidadania e os direitos humanos das mulheres.

\section{REFERÊNCIAS}

ALMEIDA, Suely S. Femicídio: algemas (in)visíveis do público-privado. Rio de janeiro: Revinter, 1998.

BIROLI, Flávia. Gênero e desigualdades: os limites da democracia no Brasil. São Paulo: Boitempo, 2018.

BLAY, Eva A. Assassinato de mulheres e Direitos Humanos. São Paulo - USP: Editora 34, 2008.

BOURDIEU, Pierre. O poder Simbólico. Rio de Janeiro: Bertrand Brasil, 1989. 
BRASIL. Lei n⿳0 13.104, de 9 de março de 2015.

CARCEDO, Ana; SAGOT, Montserrat. Femicidio en Costa Rica: 1990-1999. Colección Teórica 1. Instituto nacional de las mujeres: San José, Costa Rica, 2000.

FAIRCLOUGH, Norman. Discurso e mudança social. Brasília: Editora Universidade de Brasília, 2001.

IPEA. Atlas Da Violência 2019. Rio de Janeiro, 2018. Disponível em:

http://www.ipea.gov.br/portal/images/stories/PDFs/relatorio_institucional/190605_atlas_da_violencia _2019.pdf. Acesso em: jun/2019.

LAGARDE, Marcela. "Antropología, feminismo y política: Violenciafeminicida y derechos humanos de lasmujeres". In: BULLEN, Margaret y DÍEZ, Carmen (coords.) Retos teóricos y nuevas prácticas, Ankulegi Antropologia Elkartea, Donostia, 2008.

MELLO, Adriana R. Feminicídio: uma análise sociojurídica da violência contra a mulher no Brasil, 2. Ed. Rio de Janeiro: LMJ Mundo Jurídico, 2017.

ORLANDI, Eni P. Análise do discurso: princípios e procedimentos. 7.ed. Campinas: Pontes, 2007.

O POPULAR. Ed. 21.468, Goiás, 2012.

Ed. 21.650, Goiás, 2013.

Ed. 21.921, Goiás, 2014.

Ed. 22.386, Goiás, 2015.

Ed. 22.924, Goiás, 2016.

Ed. 23.125, Goiás, 2017.

Ed. 23.628, Goiás, 2018.

ROMIO, Jackeline. Feminicídios no Brasil, uma proposta de análise com dados do setor de saúde, 215 f. Tese (Doutorado em Demografia) - Universidade Estadual de Campinas, Campinas, 2017.

RUBIN, Gayle. The Traffic in Women. Notes on the "Political Economy" of Sex. In: REITER, Rayna (ed.) Toward an Anthropology of Women. New York, Monthly Review Press, 1975.Disponível em: https://philpapers.org/rec/RUBTTI. Acesso em: jan/2019.

SCOTT, Joan. Gênero: uma categoria útil para análise histórica. In: Educação e Sociedade, Porto Alegre, v.20, jul-dez 1995, p. 71-99. Disponível em:

https://seer.ufrgs.br/educacaoerealidade/article/view/71721. Acesso em: jan/2019.

TELES, Maria A.A. O que são direitos humanos das mulheres. São Paulo: Brasiliense. Ebook Kindle, 2017. ASIN: B074JKTG78.

THOMPSON, John B. Ideologia e cultura moderna. Petrópolis, RJ: Vozes, 2002

TRAQUINA, Nelson. O poder do jornalismo: análise e textos da teoria do agendamento. Coimbra: Minerva, 2000. 
Kamilla Cristina da Cunha Santos

É mestra em Comunicação pela Universidade Federal de Goiás, especialista em Comunicação em Redes Sociais pelas Faculdades Metropolitanas Unidas e bacharela em Comunicação Social - Jornalismo pela Universidade Federal do Pará. Estuda e pesquisa temas ligados à violência contra as mulheres, feminicídio e crítica jornalística.

Ângela Teixeira de Moraes É pós-doutora em Comunicação pela Universidade de Brasília e professora do Programa de Pós-graduação em Comunicação na Universidade Federal de Goiás. É coautora do livro Comunicação e Discursividade: teoria e dispositivos analíticos da AD. Estuda e pesquisa o jornalismo, especialmente pela ótica da teoria do discurso.

\section{@ $\odot \odot$}

Esta obra está licenciada com uma Licença

HYPERLINK "http://creativecommons.org/licenses/by-nc-sa/4.0/"Creative Commons Atribuição- 